\title{
Health-Related Quality of Life in Patients with Small Intestine Neuroendocrine Tumors
}

\section{Karppinen, Noora}

2019-01

Karppinen, N , Linden , R, Sintonen , H, Tarkkanen , M , Roine , R, Heiskanen , I , Matikainen , N \& Schalin-Jäntti , C 2019 , ' Health-Related Quality of Life in Patients with Small Intestine Neuroendocrine Tumors ' , Neuroendocrinology : international journal for basic and clinical studies on neuroendocrine relationships , vol. 107 , no. 4 , pp. 366-374 . https://doi.org/10.1159/00

http://hdl.handle.net/10138/313102

https://doi.org/10.1159/000494293

acceptedVersion

Downloaded from Helda, University of Helsinki institutional repository.

This is an electronic reprint of the original article.

This reprint may differ from the original in pagination and typographic detail.

Please cite the original version. 
$\mathbb{N e r u r o}$ endocrinology

E E E

$$
\begin{aligned}
& \begin{array}{ccccccccccc}
M P & M P & M P & I & M P & P & P & M & P & P & \\
M & I & & P & M & M & & & & M & M P
\end{array} \\
& \text { P } M \quad P \quad E
\end{aligned}
$$

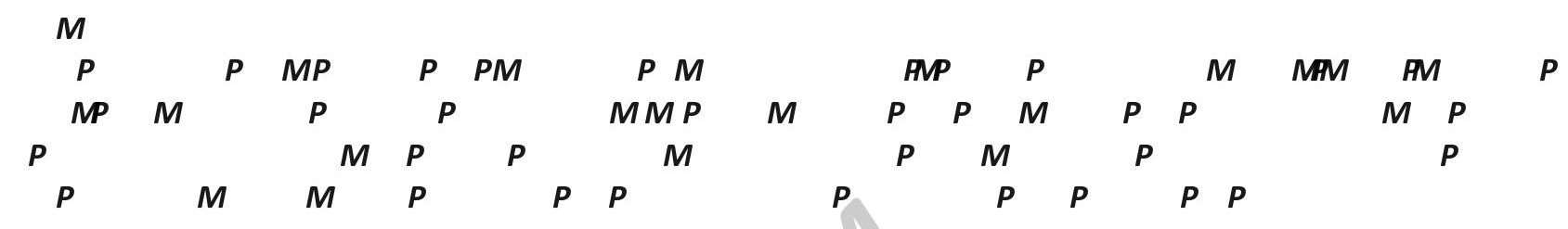

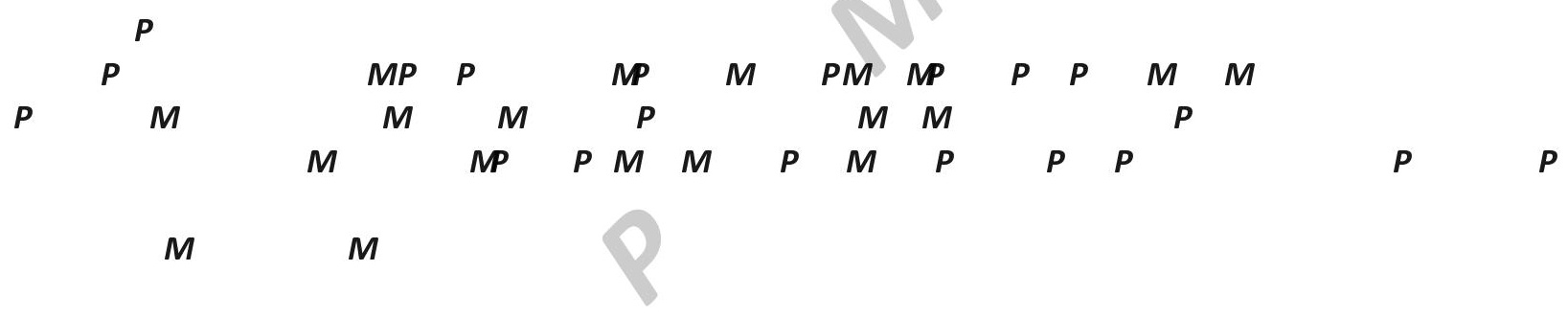




\section{Health-Related Quality of Life in Patients with Small Intestine}

\section{Neuroendocrine Tumours}

Noora Karppinen ${ }^{1}$, Riikka Lindén ${ }^{2}$, Harri Sintonen ${ }^{3}$, Maija Tarkkanen $^{4}$, Risto Roine ${ }^{5}$, Ilkka Heiskanen ${ }^{6}$, Niina Matikainen $^{1 *}$, Camilla Schalin-Jäntti ${ }^{1 *}$

${ }^{1}$ Endocrinology, Abdominal Center, Helsinki University Hospital and University of Helsinki, Finland

${ }^{2}$ Department of Radiology, HUS Medical Imaging Centre, Helsinki University Hospital, Helsinki, Finland

${ }^{3}$ Department of Public Health, University of Helsinki, Finland

${ }^{4}$ Comprehensive Cancer Center, Helsinki University Hospital, Finland

${ }^{5}$ Group Administration, University of Helsinki and Helsinki University Hospital, Finland, and Department of Health and Social Management, Research Centre for Comparative Effectiveness and Patient Safety,

University of Eastern Finland and Kuopio University Hospital, Finland

${ }^{6}$ Endocrine surgery, Abdominal Center, Helsinki University Hospital, Finland

*joint senior authorship

Short running title: Quality of Life in Patients with SI-NET

Correspondence: Camilla Schalin-Jäntti, Endocrinology, Abdominal Center, University of Helsinki and Helsinki University Hospital, P.O BOX 340, FI-00290 Helsinki, Finland, Tel +358 947172589 , Fax +358 9 47175798, Email camilla.schalin-jantti@hus.fi

Disclosure statement: The authors have nothing to disclose.

Word count: 3095

Keywords: Health-related quality of life, Small intestine neuroendocrine tumour, Carcinoid syndrome, Depression, Diarrhea, 5HIAA, CgA 


\begin{abstract}
Background: The prevalence of small intestine neuroendocrine tumours (SI-NETS) is increasing. Disease progression is often slow and treatment options and long-term survival rates have improved, but little is known about health-related quality of life (HRQoL) in these patients.

Objective: To assess HRQoL and its predictors in SI-NET patients receiving contemporary treatments.

Methods: We measured HRQoL with 15D and SF-36 questionnaires in 134 SI-NET patients and compared the $15 \mathrm{D}$ results to those of age- and gender-standardized general population $(n=1153)$. In the patients, we studied impact of treatments, Ki67, liver metastases, circulating tumour markers, comorbidities and/or socioeconomic factors on $\mathrm{HRQ}$ oL with linear regression analysis.

Results: Mean disease duration of the patients was 81 (4-468) months, $91 \%$ had metastatic disease and $79 \%$ received somatostatin analog treatment. Hepatic tumour load was $0 \%$ in $44.8 \%,<10-25 \%$ in $44.0 \%$, and $>25 \%$ in $11.2 \%$, respectively. Mean fP-CgA and S-5HIAA concentrations were $15(1.3-250) \mathrm{nmol} / \mathrm{l}$ and 344 (24-7470) nmol/l, respectively. Overall HRQoL was significantly impaired in patients compared to controls (15D scores $0.864 \pm 0.105$ vs $0.905 \pm 0.028, p<0.001)$. SI-NET patients scored worse on 9 of 15 dimensions (sleep, excretion (ie bladder and bowel function), depression, distress, vitality, sexual activity $(p<0.001)$, breathing, usual activities, and discomfort and symptoms $(p<0.01-0.05)$. SF-36 scores were impaired and highly correlated with 15D scores $(p<0.001)$. HRQoL was impaired in patients with $(n=85)$ compared to patients without $(n=49)$ impaired excretion $(0.828$ vs $0.933, p<0.001)$. In the patient group, number of medications predicted impaired HRQoL.
\end{abstract}

Conclusions: Despite contemporary treatments, SI-NET patients have severely impaired HRQoL, including diarrhea, sleep, depression, vitality and sexual activity. 


\section{Introduction}

Small intestine neuroendocrine tumours (SI-NETs) arise from neuroendocrine cells in the jejunum or ileum and typically secrete bioactive peptides. Currently, increasing incidences in the range of 0.5-1.5 per 100.000 inhabitants and year are reported [1-4]. Most tumours are grade 1 and 2, defined by a Ki67 index of $\leq 2 \%$ and $2-20 \%$, respectively [5]. They are characterized by relatively slow tumour progression and long overall survival [1]. Surgery is the cornerstone of treatment and advancements in systemic treatment options, including somatostatin analog and interferon therapy, everolimus, and peptide receptor radionuclide therapy (PRRT) have further improved survival rates in patients with SI-NETs. SI-NETs commonly produce serotonin and, when metastasized to the liver, patients may develop carcinoid syndrome including diarrhea, flushing, bronchospasm and, in the advanced stage, cardiac valvular fibrosis and right-sided heart failure. [6]

Reports of improved survival rates indicate that important therapeutic goals have been achieved for this patient group. The somatostatin analogs octreotide and lanreotide efficiently improve symptoms of diarrhea and flushing. In selected patients, debulking of liver metastases, ablative therapies and other liver-directed modalities may also relieve symptoms and hormonal overproduction. Quality of life is considered an important measure of patients' perception of the burden of their disease and the impact of treatment modalities. Despite this, data on health-related quality of life (HRQoL) in patients with SI-NETs are scarce.

In this study, we compare HRQoL in a cohort of carefully characterized SI-NET patients from a single center, and compare the results to those of a large sample of the general population. Within the patient group, we searched for predictors of HRQoL.

\section{Patients and Methods}

\section{Subjects}

Patients. Patients with a histologically confirmed diagnosis of SI-NET treated at the Division of Endocrinology and Department of Oncology, Helsinki University Hospital (HUH) during year 2017 were invited to participate in the study. Because all patients operated on for neuroendocrine tumours are referred either to the Endocrinology or Oncology unit at HUH. These subjects represent the majority of/all SI-NET patients in the $\mathrm{HUH}$ area. Only patients with available data on pathologic, radiologic and biochemical parameters were included. We identified a total of 211 subjects from our electronic patient records with the diagnosis of SINET or carcinoid syndrome (ICD-codes E17.9 or E34.0). Thirty subjects were excluded from the study. Of them, ten had another severe disease (cognitive impairment, severe heart failure due to other cause than carcinoid heart, other malignancy) and two were in palliative care. Six subjects had deceased within the year. Clinical data was not available for twelve subjects who had been referred to our multidisciplinary NET tumour board for consultation.

An invitation letter, the 15D and the SF36 questionnaires, and a supplementary questionnaire (Supplementary questionnaire) were sent in June 2017 to 181 patients identified from our electronic patient records. An additional letter was sent to all non-responders within 4-6 weeks. Biochemical and clinical data,comorbidities (cardiovascular disease, diabetes, depression which were taken into account if a patient was taking a medication for them) were retrieved from our electronic patient records. Pathology reports were collected from the electronic patient records.

Control population. The results obtained with the 15D instrument were compared to those of a large ageand gender-standardized sample of the Finnish general population from the Finnish Health 2011 survey $(n=1153)$ [7]. This sample was from the same catchment area as the patients. 


\section{Ethics}

The study was approved by the ethics committee of Helsinki University Hospital. All patients gave their signed informed consent for participation in the study.

\section{HRQoL Assessment}

The 15D questionnaire is a generic, standardized, well-validated, self-administered measure of HRQoL for persons aged 16 or more [8]. 15D was chosen as it also measures the dimension of excretion, in contrast to SF-36, and as the results could be compared to those of a large age- and gender-standardized general population. The 15D proved to be the best generic HRQoL instrument regarding sensitivity and construct validity in a study by Richardson et al., comparing six different generic tests, including the SF-6 [9]. The 15D can be used both as a profile and a single score measure. The questionnaire consists of 15 dimensions: mobility, vision, hearing, breathing, sleeping, eating, speech, excretion (includes both bladder and bowel function), usual activities, mental function, discomfort and symptoms, depression, distress, vitality and sexual activity. Each dimension is divided into five levels and respondents choose the level best describing their current health status (for the 15D questionnaire, see Supplementary data). The 15D score and the dimensional level values (on a 0-1 scale) are calculated from the health state descriptive system by using a set of population-based preference or utility weights. This allows calculation of the 15D score representing the overall HRQoL. A higher score reflects a better HRQoL. The minimum important change for the 15D score is estimated to be \pm 0.015 and 0.015 can also be regarded as the minimum clinically important cross-sectional difference between groups [10].

The SF-36 is a questionnaire measuring self-reported HRQoL in 8 dimensions: physical functioning, role limitations due to physical health, role limitations due to emotional problems, vitality, mental health, social functioning, bodily pain and general health. HRQoL scores are presented on a 0-100 scale. A higher score indicates better HRQoL. [11]

In addition, the patients answered a short supplementary questionnaire (Supplementary questionnaire, see Supplementary data) including questions on marital status, educational level, symptoms (diarrhea, flushing, abdominal pain, defecation frequency) and regular medication.

\section{Assessment of hepatic tumour burden}

An experienced radiologist (R.L) re-assessed hepatic tumour burden of the SI-NET patients who answered the questionnaires employing CT (98 patients), MRI (28 patients), or ${ }^{68} \mathrm{Ga}$-Dotanoc PET/CT (8 patients) if no CT or MRI scans were available. Tumour burden was estimated using a visual semi-quantitative approach. This method has previously been applied in other studies on patient with NETs [12,13]: 4-6 scan slices with the most extensive affection were selected and scored visually for the extent of the disease. In case of multiple scans of the same patient, we chose the scan timely closest to the date of the HRQoL questionnaires. Hepatic tumour burden was divided into five categories: $0 \%,<10 \%, 10-25 \%, 25-50 \%$ and $>50 \%$.

\section{Laboratory Measurements}

All laboratory analyses, including serum 5-hydroxyindoleacetic acid (S-5HIAA) were performed at the Helsinki University Hospital Laboratory, HUSLAB, using in-house methods. Plasma chromogranin A (fP-CgA) was measured by radioimmunoassay. S-5HIAA was measured by liquid chromatography - mass spectrometry [14].

\section{Statistical Analysis}

Statistical analysis was performed with IBM SPSS Statistics 24 for Windows. Independent samples t-test was used to test the statistical significance of the differences in the means between SI-NET patients and controls 
from the general population. Independent samples t-test was also used to evaluate the impact of a single determinant (age, gender, educational level, use of somatostatin analog, hepatic metastases, fP-CgA level, S5HIAA level, PRRT, interferon, Ki67, comorbidities (cardiovascular disease, diabetes and depression), number of regular medications, diarrhea and flushing) on HRQoL. Linear regression analysis was used to evaluate the association between HRQoL and age, gender, educational level, use of somatostatin analog, S-5HIAA concentration, PRRT, interferon, Ki67, liver metastases, comorbidities (cardiovascular disease, diabetes) and number of regular medications. Correlations were analyzed with Pearson correlation coefficient. All provided $p$-values are two-sided and a p-value of $<0.05$ was considered statistically significant. The results are given as mean and standard deviation, or as percentages.

\section{Results}

\section{Patient characteristics}

The response rate was $74 \%$ with 134/181 patients answering the 15D and SF-36 questionnaires. Patient characteristics are given in Table 1. The mean age of the 134 respondents was $66.8 \pm 9.9$ years and $55 \%$ of them were women. Mean disease duration was $81 \pm 74$ months. One-hundred and twenty-two patients (91\%) had either locally advanced or metastatic disease. S-5HIAA was normal (reference range <123 nmol/l) in 69 patients (52\%). The primary tumour had been operated in 126 patients $(94 \%)$. One-hundred and six patients (79\%) received somatostatin analog therapy. Thirty-six of the 134 patients had undergone PRRT. Other medical treatments included interferon and chemotherapy (Table 1). Eighty-five patients (63\%) suffered from diarrhea ( $3.3 \pm 2.6$ times per week) and 42 patients ( $31 \%$ ) from flushing ( $2.4 \pm 3.4$ times per week).

Patients not answering the questionnaires ( $n=47(26 \%)$, age $62.7 \pm 13.4,49 \%$ women) did not differ significantly from those returning the questionnaires regarding age or gender.

Health-related quality of life in SI-NET patients compared to the general population

15D. The mean (SD) 15D score was significantly lower in SI-NET patients compared to that of the age- and gender-standardized general population ( $0.864 \pm 0.105$ vs. $0.905 \pm 0.028, p<0.001$; Figure 1 ). This difference is also clinically important [10]. When comparing single dimensions, SI-NET patients had significantly impaired $\mathrm{HRQoL}$ on 9 of the 15 dimensions (excretion, sleeping, depression, distress, vitality, sexual activity (all $\mathrm{p}<0.001$ ), breathing, usual activities (both $\mathrm{p}<0.01$ ), and discomfort and symptoms (both $\mathrm{p}<0.05$ )). (Figure 1 ).

SF-36. The mean SF-36 scores in SI-NET patients were: physical functioning $78 \pm 23$, role limitations due to physical health $64 \pm 41$, role limitations due to emotional problems $71 \pm 38$, vitality $63 \pm 21$, mental health $78 \pm 17$, social functioning $80 \pm 20$, bodily pain $73 \pm 25$ and general health $55 \pm 21$. There was a significant positive correlation between the 15D score and the SF-36 dimension scores on all eight dimensions. The Pearson correlation coefficients for 15D score and SF-36 dimensions were as follows: physical functioning 0.704 , role limitations due to physical health 0.637 , role limitations due to emotional problems 0.571 , vitality 0.744 , mental health 0.665 , social functioning 0.699 , bodily pain 0.511 and general health 0.665 , for all $p<0.001$.

\section{Predictors of HRQoL in SI-NET patients}

Within the patient group, only number of medications predicted impaired HRQoL in linear regression model (Table 2). HRQoL was not affected by the somatostatin analog in use (long-acting lanreotide vs long-acting octreotide, data not shown). The adjusted $\mathrm{R}$ square for the mean total 15D score reflecting overall HRQoL was 0.251 . As fP-CgA and S-5HIAA correlated significantly, fP-CgA was left out from the analysis.

\section{Health-Related Quality of Life in Patients with and without Impaired Excretion}

Excretion, which includes both bladder and bowel function, correlated closely with self-reported diarrhea $(r=-0.506, p<0.001)$. This dimension was compared in SI-NET patients with impairments (levels 2-5, corresponding to 15D score $\leq 0.8$ ) and those with normal function (Level 1, "My bladder and bowel work 
normally and without problems"). Clinical characteristics of SI-NET patients with and without impaired excretion are presented in Table 3. The mean (SD) 15D score was significantly lower in patients with impaired compared to normal excretion $(0.828 \pm 0.103$ vs. $0.933 \pm 0.067, p<0.001$; Figure 2$)$. The difference is also clinically important [10]. Patients with impaired excretion had a significantly higher number of defecation times per day $(p<0.001)$ and more often suffered from diarrhea $(p<0.001)$ compared to patients with normal excretion. Patients with impaired excretion used a significantly higher number of medications $(p<0.01)$. Patients with normal excretion had higher Ki-67 proliferation index $(p<0.05)$.

Patients with impaired excretion also demonstrated significantly lower dimension scores in all but one SF-36 (mental health) dimension compared to patients with normal excretion (Table 4).

Patients with self-reported diarrhea (supplementary questionnaire) had significantly lower mean (SD) 15D score $(0.843 \pm 0.105$ vs $0.901 \pm 0.095, p<0.01)$ compared to patients not reporting diarrhea, and significant impairments in 6 of the 15 single dimensions (excretion ( $p<0.001)$; breathing and discomfort and symptoms $(p<0.01)$; mobility, mental function and vitality $(p<0.05))$ compared to patients not reporting diarrhea.

\section{Discussion}

In the present cross-sectional study, we found that SI-NET patients are characterized by significantly impaired HRQoL compared to a large control population of more than 1000 persons from the same catchment area despite contemporary treatments. The SI-NET patients had histologically verified disease and were treated at a single center. This enabled us to estimate the impact of a large number of factors such as disease duration, treatment modalities, comorbidities, liver metastases, Ki67 proliferation index, as well as circulating neuroendocrine tumour markers on HRQoL. Novel findings of the present study are that the dimensions of excretion, sleep, depression, distress, vitality and sexual activity all are severely impaired in patients with SI-NETs.

Some previous studies in patients with NETs of mixed origins also demonstrated impaired HRQoL [15-19]. A Norwegian study included patients with NET tumours from any part of the gastrointestinal tract $(n=196)$ [17], a Swedish study defined the patients as having carcinoid tumour but included 36 patients only [16]. A large online anonymous survey performed in the USA reported reduced quality of life in a cohort of 663 subjects with self-reported diagnoses of carcinoid, islet cell or unknown underlying tumour [18]. The authors concluded that optimal management of NETs and carcinoid syndrome may significantly improve HRQoL among patients with NETs [18]. So far, only one previous study has reported equivalent HRQoL in the subgroup of SI-NET patients compared to a normative population [20]. However, the number of SI-NET patients in that study was small $(n=44)$ and approximately $40 \%$ of the patients were in remission. In the present study, $91 \%$ had local or distant metastases which may explain the lower HRQoL compared to that of the general population in our study.

Approximately $60 \%$ of SI-NET patients have metastatic disease already at diagnosis [6], most commonly including mesenteric and para-aortic lymph nodes and the liver. In patients with SI-NETs, liver and retroperitoneal metastases impair prognosis and generally introduce symptoms related to hypersecretion of serotonin and its breakdown products, as these bioactive peptides cannot be cleared by the liver. Carcinoid syndrome is found in approximately $30 \%$ of SI-NET patients at diagnosis and is characterized by diarrhea, flushing, bronchoconstriction and fatigue. Average disease duration in the present study was 81 months and a majority had metastatic disease. We therefore wanted to study the impact of circulating 5HIAA concentrations and liver metastases on HRQoL. However, neither 5HIAA concentrations nor hepatic tumour burden independently predicted HRQoL in the present study.

Diarrhea as a disease specific symptom in Si-NET was further characterized by dividing the patients in those with and those without impaired excretion score on 15D. Both mean SF-36 and 15D scores were significantly lower in patients with impaired excretion compared to patients without impaired excretion. In addition, mean 15D scores were significantly lower in patients with self-reported diarrhea compared to patients 
without diarrhea. This strengthens the finding that carcinoid syndrome and, especially, diarrhea impair HRQoL in SI-NET patients.

The clinical factors studied here did not clarify the cause of diarrhea. In Si-NET patients, causes of diarrhea are multifactorial. In addition to carcinoid syndrome, HRQoL may be related to gender, extent of bowel surgery, medications or other underlying diseases [21]. To our surprise, the two groups with and without impaired excretion did not differ with regard to age, biochemical disease control, hepatic tumour burden, or treatments. Neither did the two groups differ regards resection of the primary tumour (resected in the majority of patients, 94\%). Patients with impaired excretion had a higher number of medications. The underlying tumour in this group was characterized by a slightly, but significantly, lower Ki-67 proliferation index indicating that Ki-67 does not directly correlate with hormonal hypersecretion and carcinoid syndrome symptoms in SI-NETs.

The significance of the impaired excretion score and self-reported diarrhea for HRQoL in our patient group is somewhat surprising, as our patients receive contemporary therapy according to recent European treatment guidelines [22]. Altogether $79 \%$ of the patients in the present study are on somatostatin analog therapy, known not only to improve diarrhea and decrease fP-CgA and S-5HIAA concentrations, but also to have an anti-tumoural effect $[12,13]$. Our results imply that better treatments of diarrhea are warranted in SI-NET patients. Telotristat ethyl is a new drug for patients suffering from carcinoid syndrome, the current indication being diarrhea not adequately responding to somatostatin analog treatment [23]. Gelhorn et al and Kulke et al [24] reported that telotristat ethyl improves diarrhea and decreases bowel movement frequency in patients with carcinoid syndrome.

In addition to impaired excretion, also depression, sleep, distress, vitality and sexuality were significantly impaired. Currently, as these impairments have not been acknowledged, they render little if any attention in the clinical follow-up and treatment of SI-NET patients. The prevalence of depression and anxiety in carcinoid syndrome is approximately $50 \%$ and $35 \%$, respectively [25-27]. A case report indicated that telotristat ethyl in combination with a low dose selective serotonin reuptake inhibitor ameliorated diarrhea and depression in somatostatin analog treatment resistant carcinoid syndrome [28]. Further studies are needed to clarify this issue. Better treatment of depression, sleeping problems and sexual health thus seem to be other important targets in the management of SI-NET patients in the future. The finding of larger number of medications as a predictor of HRQoL in the present study may reflect symptomatic treatments of diarrhea and depression or other comorbidities in this subgroup.

We also assessed the effect of PRRT, also known to improve prognosis, on HRQoL. In total, 36 of the patients had received PRRT. Even though PRRT is indicative of advanced and progressive disease, it did not predict or correlate with impaired HRQoL in our study. However, the effect of PRRT is best evaluated in a prospective setting. Earlier studies evaluating HRQoL in patients receiving PRRT demonstrated that this treatment actually improves HRQoL in NET patients [29-31] and attenuates symptoms related to the carcinoid syndrome [30-32].

We have previously used the 15D instrument when investigating HRQoL in other endocrine tumour diseases such as thyroid carcinoma [33], pituitary adenomas [34,35] and primary hyperparathyroidism [36]. Previous studies reporting impaired HRQoL in patients with NETs have utilized the SF-36 and EORTC QLQ-C30 [15-18]. In the present study, we used both the 15D and SF-36 and the results were highly correlated. An important limitation of the SF-36 is that it does not assess excretion. To the extent that the SF-36 can be regarded as a gold standard for measuring HRQoL in this patient group, the 15D therefore can be regarded as even better. The 15D is a generic, standardized and well-validated test for measuring HRQoL. Importantly, as many patients with SI-NETs suffer from symptoms that are common in the general population, such as depression and irritable bowel disease, a comparison of the findings in patients compared to a well-characterized and representative control population is essential. The 15D thus enabled us to compare HRQoL in SI-NET patients to that of a large age- and gender-standardized population. 
An important limitation of the current study is that it is cross-sectional and observational. We could not adjust the $15 \mathrm{D}$ results of the control population for comorbidities or socioeconomic factors. Naturally, in order to evaluate the prognostic significance of our findings, a longitudinal prospective follow-up study on carefully characterized patients with SI-NETs should be performed.

In conclusion, we demonstrate that patients with SI-NETs have severely impaired HRQoL despite contemporary treatments. Current treatment options have resulted in prolonged survival rates but better treatment of depression, diarrhea, possible disturbances in sleep and sexual activity is warranted in the future.

\section{Author contributions}

HS, RR, NM and CSJ designed the study. NM, MT and IH collected the patients. NM and NK collected the clinical data. RL analyzed hepatic tumour burden. NK, RR and HS performed the statistical analyses. NK, NM and CSJ drafted and wrote the manuscript. All authors participated in writing the final version. 


\section{References}

1. Yao JC, Hassan M, Phan A, Dagohoy C, Leary C, Mares JE, Abdalla EK, Fleming JB, Vauthey J, Rashid A, Evans DB. One hundred years after "Carcinoid": Epidemiology of and prognostic factors for neuroendocrine tumors in 35,825 cases in the united states. 미. 2008;26(18):3063-3072.

2. Lawrence B, Gustafsson BI, Chan A, Svejda B, Kidd M, Modlin IM. The epidemiology of

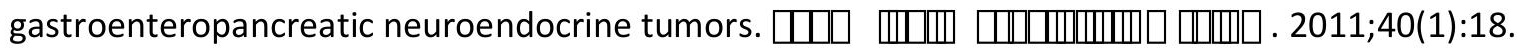

3. Hallet J, Law CHL, Cukier M, Saskin R, Liu N, Singh S. Exploring the rising incidence of neuroendocrine tumors: A population-based analysis of epidemiology, metastatic presentation, and outcomes. 미 $\mathrm{C}$. 2015;121(4):589-597.

4. Dasari A, Shen C, Halperin D, Zhao B, Zhou S, Xu Y, Shih T, Yao JC. Trends in the incidence, prevalence,

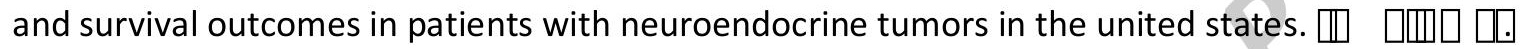
2017;3(10):1335-1342.

5. Klöppel G. Classification and pathology of gastroenteropancreatic neuroendocrine neoplasms.

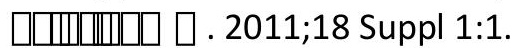

6. Janson ET, Sorbye H, Welin S, Federspiel B, Grønbæk H, Hellman P, Ladekarl M, Langer SW, Mortensen J, Schalin-Jäntti C, Sundin A, Sundlöv A, Thiis-Evensen E, Knigge U. Nordic guidelines 2014 for diagnosis and

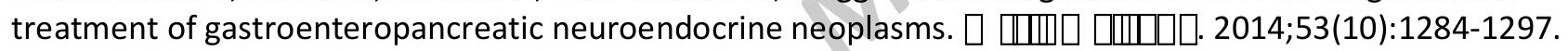

7. Koskinen S, Lundqvist A, Ristiluoma N (eds) 2012 Health, Functional Capacity and Welfare in Finland in 2011. National Institute for Health and Welfare (THL), Report 68/2012; Helsinki 2012.

8. Sintonen H. The 15D instrument of health-related quality of life: Properties and applications. 2001;33(5):328-336.

9. Richardson J, lezzi A, Khan MA, Chen G, Maxwell A. Measuring the Sensitivity and Construct Validity of 6

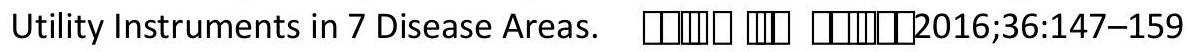

10. Alanne $S$, Roine RP, Räsänen $P$, Vainiola $T$, Sintonen $H$. Estimating the minimum important change in the

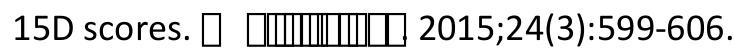

11. Ware JE, Sherbourne CD. The MOS 36-item short-form health survey (SF-36). I. conceptual framework

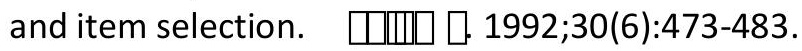

12. Rinke A, Müller H, Schade-Brittinger C, Klose K, Barth P, Wied M, Mayer C, Aminossadati B, Pape UF, Bläker M, Harder J, Arnold C, Gress T, Arnold R. Placebo-controlled, double-blind, prospective, randomized study on the effect of octreotide LAR in the control of tumor growth in patients with

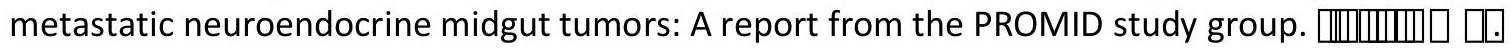
2009;27(28):4656-4663.

13. Caplin ME, Pavel M, Ćwikła JB, Phan AT, Raderer M, Sedláčková E, Cadiot G, Wolin EM, Capdevila J, Wall L, Rindi G, Langley A, Martinez S, Blumberg J, Ruszniewski P. Lanreotide in metastatic enteropancreatic

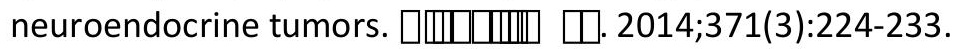


14. Tohmola N, Itkonen O, Sane T, Markkanen H, Joenväärä S, Renkonen R, Hämäläinen E. Analytical and preanalytical validation of a new mass spectrometric serum 5-hydroxyindoleacetic acid assay as

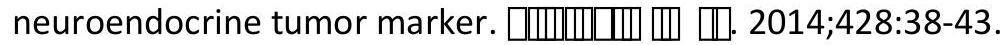

15. Larsson G, Sjödén PO, Oberg K, Eriksson B, von Essen L. Health-related quality of life, anxiety and

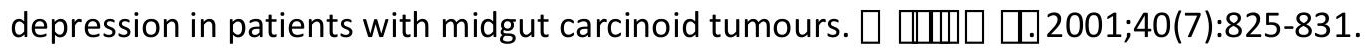

16. Fröjd C, Larsson G, Lampic C, von Essen L. Health related quality of life and psychosocial function among patients with carcinoid tumours. A longitudinal, prospective, and comparative study.

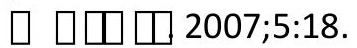

17. Haugland $T$, Vatn $M H$, Veenstra $M$, Wahl AK, Natvig GK. Health related quality of life in patients with

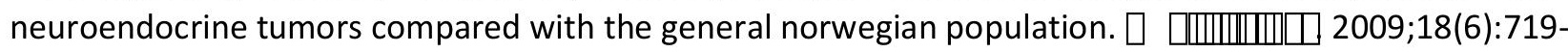
726.

18. Beaumont JL, Cella D, Phan AT, Choi S, Liu Z, Yao JC. Comparison of health-related quality of life in patients with neuroendocrine tumors with quality of life in the general US population. ! ए ए 2012;41(3):461-466.

19. Pearman TP, Beaumont JL, Cella D, Neary MP, Yao J. Health-related quality of life in patients with neuroendocrine tumors: An investigation of treatment type, disease status, and symptom burden. "\#叫

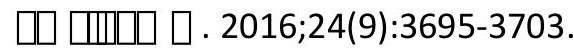

20. Pezzilli R, Campana D, Morselli-Labate AM, Galassi E, Brocchi E, Nori F, Cipollini ML, Tomassetti P.

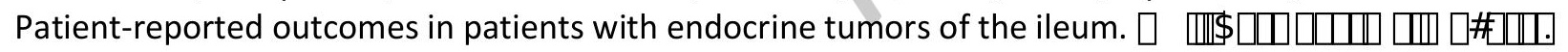
2010;22(6):689-694.

21. Milanetto AC, Nordenström E, Sundlöv A, Amquist M. Health-Related Quality of Life After Surgery for

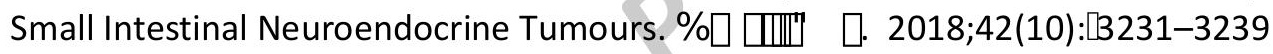

22. Pavel M, O'Toole D, Costa F, Capdevila J, Gross D, Kianmanesh R, Krenning E, Knigge U, Salazar R, Pape UF, Öberg K. ENETS consensus guidelines update for the management of distant metastatic disease of intestinal, pancreatic, bronchial neuroendocrine neoplasms (NEN) and NEN of unknown primary site.

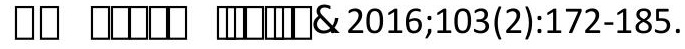

23. Gelhorn HL, Kulke MH, O'Dorisio T, Yang QM, Jackson J, Jackson S, Boehm KA, Law L, Kostelec J, Auguste $P$, Lapuerta P. Patient-reported symptom experiences in patients with carcinoid syndrome after

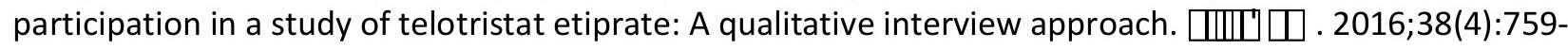
768.

24. Kulke MH, Hörsch D, Caplin ME, Anthony LB, Bergsland E, Öberg K, Welin S, Warner RR, Lombard-Bohas C, Kunz PL, Grande E, Valle JW, Fleming D, Lapuerta P, Banks P, Jackson S, Zambrowicz B, Sands AT, Pavel M.

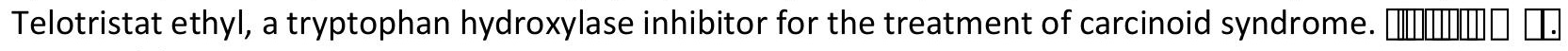
2017;35(1):14-23.

25. Williams MD, Dolenc TJ. Selective serotonin reuptake inhibitors and patients with carcinoid tumor.

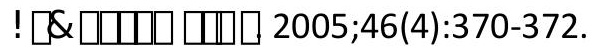

26. Major LF, Brown GL, Wilson WP. Carcinoid and psychiatric symptoms. " $\square$ 而 $\square$. 1973;66(7):787-790. 
27. Simbera Z, Balon R. Carcinoid tumor, selective serotonin reuptake inhibitors, and diarrhea. ! स\&पण口ण 2005;46(1):88-89.

28. Nobels A, Geboes K, Lemmens GMD. May depressed and anxious patients with carcinoid syndrome benefit from treatment with selective serotonin reuptake inhibitors (SSRIs)?: Findings from a case report.

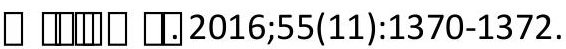

29. Teunissen JJM, Kwekkeboom DJ, Krenning EP. Quality of life in patients with gastroenteropancreatic

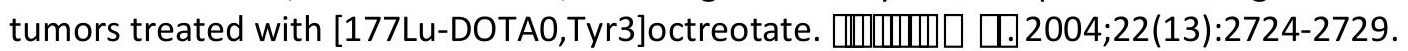

30. Khan S, Krenning EP, van Essen M, Kam BL, Teunissen JJ, Kwekkeboom DJ. Quality of life in 265 patients with gastroenteropancreatic or bronchial neuroendocrine tumors treated with [177Lu-

DOTA0,Tyr3]octreotate. 2011;52(9):1361.

31. Delpassand ES, Samarghandi A, Zamanian S, Wolin EM, Hamiditabar M, Espenan GD, Erion JL, O'Dorisio TM, Kvols LK, Simon J, Wolfangel R, Camp A, Krenning EP, Mojtahedi A. Peptide receptor radionuclide therapy with 177Lu-DOTATATE for patients with somatostatin receptor-expressing neuroendocrine tumors: The first US phase 2 experience. ! ए एव 2014;43(4):518-525.

32. Forrer F, Waldherr C, Maecke HR, Mueller-Brand J. Targeted radionuclide therapy with 90Y-DOTATOC in

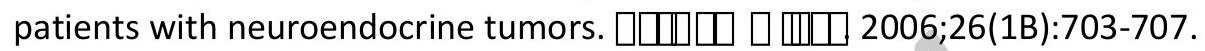

33. Pelttari H, Sintonen H, Schalin-Jäntti C, Välimäki MJ. Health-related quality of life in long-term follow-up

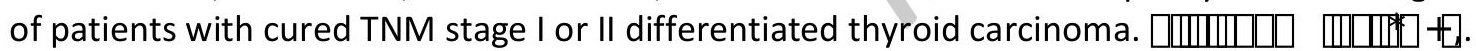
2009;70(3):493-497.

34. Karppinen A, Ritvonen E, Roine R, Sintonen H, Vehkavaara S, Kivipelto L, Grossman AB, Niemelä M, Schalin-Jäntti $C$. Health-related quality of life in patients treated for nonfunctioning pituitary adenomas

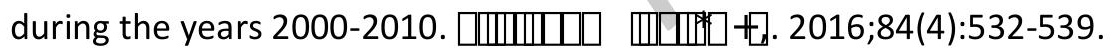

35. Ritvonen E, Karppinen A, Sintonen H, Vehkavaara S, Kivipelto L, Roine RP, Niemelä M, Schalin-Jäntti C. Normal long-term health-related quality of life can be achieved in patients with functional pituitary

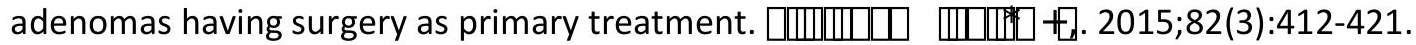

36. Ryhänen EM, Heiskanen I, Sintonen H, Välimäki MJ, Roine RP, Schalin-Jäntti C. Health-related quality of life is impaired in primary hyperparathyroidism and significantly improves after surgery: A prospective

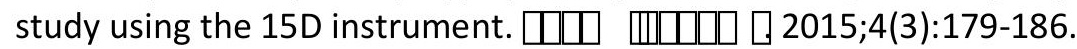

\section{Acknowledgements}

We thank study nurses Päivi Koskinen and Heli Sarpila for skillful technical assistance. This work was financially supported by the Helsinki University Hospital Research Funds (TYH2016129 and TYH2017138), Finska Läkaresällskapet and Ipsen Nordic (to C.S-J) and Juhani Aho Foundation (to NM). 


\section{Appendix}

1) The 15D Questionnaire

2) Supplementary questionnaire 


\section{Figure legends}

Fig. 1. The 15D scores and profiles of SI-NET patients $(n=134)$ and general population controls standardized for age and gender $(n=1153)$. Move $=$ mobility, See $=$ vision, Hear $=$ hearing, Breath $=$ breathing, Sleep $=$ sleeping, Eat $=$ eating, Excret $=$ excretion, Uact $=$ usual activities, Mental $=$ mental function, Disco $=$ discomfort and symptoms, Depr $=$ depression, Distr $=$ distress, Vital $=$ vitality and Sex $=$ sexual activity. ${ }^{*} p<0.05, * * p<0.01, * * * p<0.001$.

Fig. 2. The 15D scores and profiles of SI-NET patients according to excretion. Move = mobility, See = vision, Hear $=$ hearing, Breath = breathing, Sleep = sleeping, Eat $=$ eating, Excret $=$ excretion, Uact $=$ usual activities, Mental $=$ mental function, Disco $=$ discomfort and symptoms, Depr $=$ depression, Distr $=$ distress, Vital $=$ vitality and Sex $=$ sexual activity. ${ }^{*} p<0.05,{ }^{* *} p<0.01,{ }^{* * *} p<0.001$. 


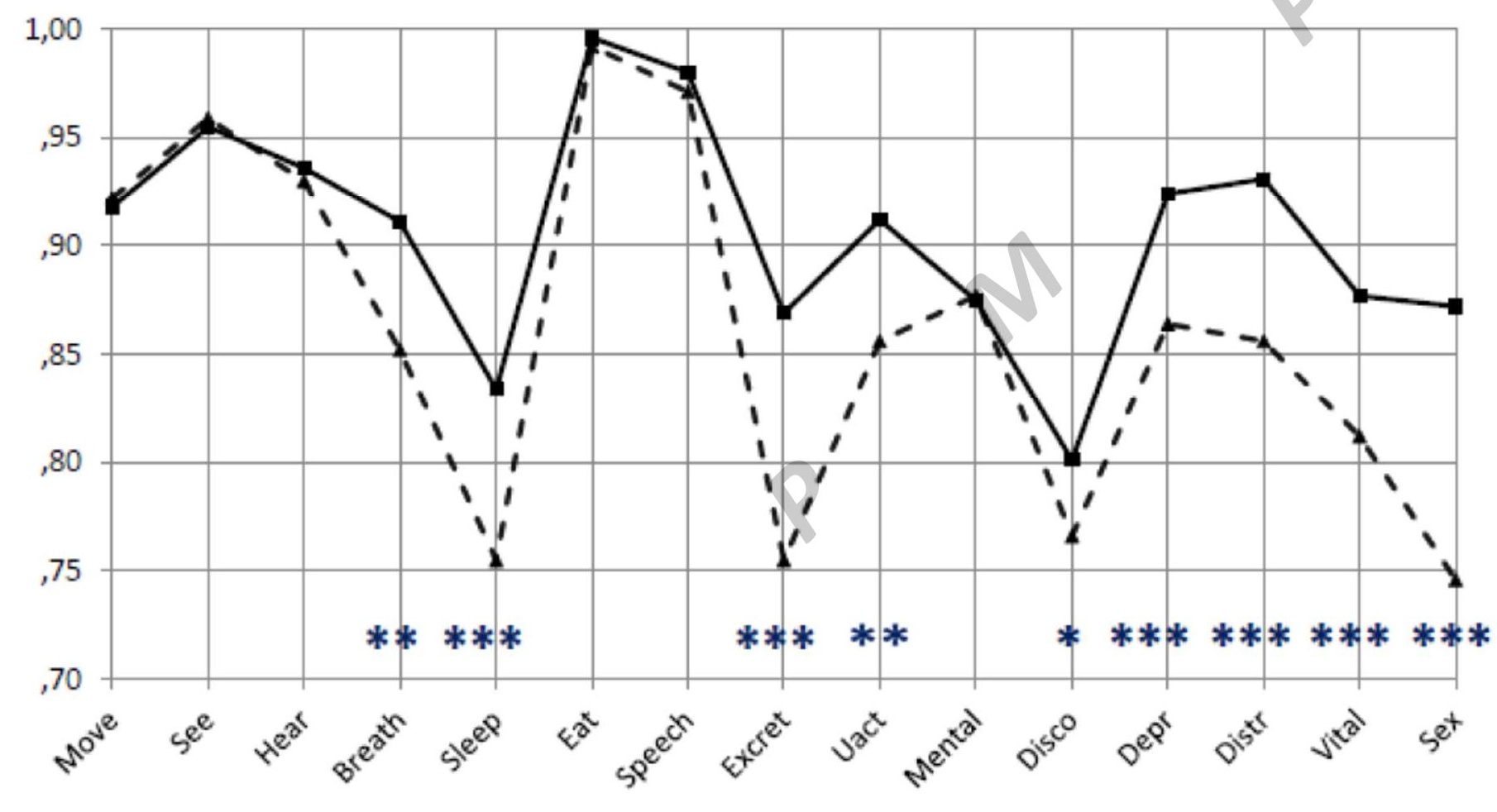

Mean 15D score

General population 0.905

SI-NET patients

0.864 $p<0.001$

- General population

- • - SI-NET patients 


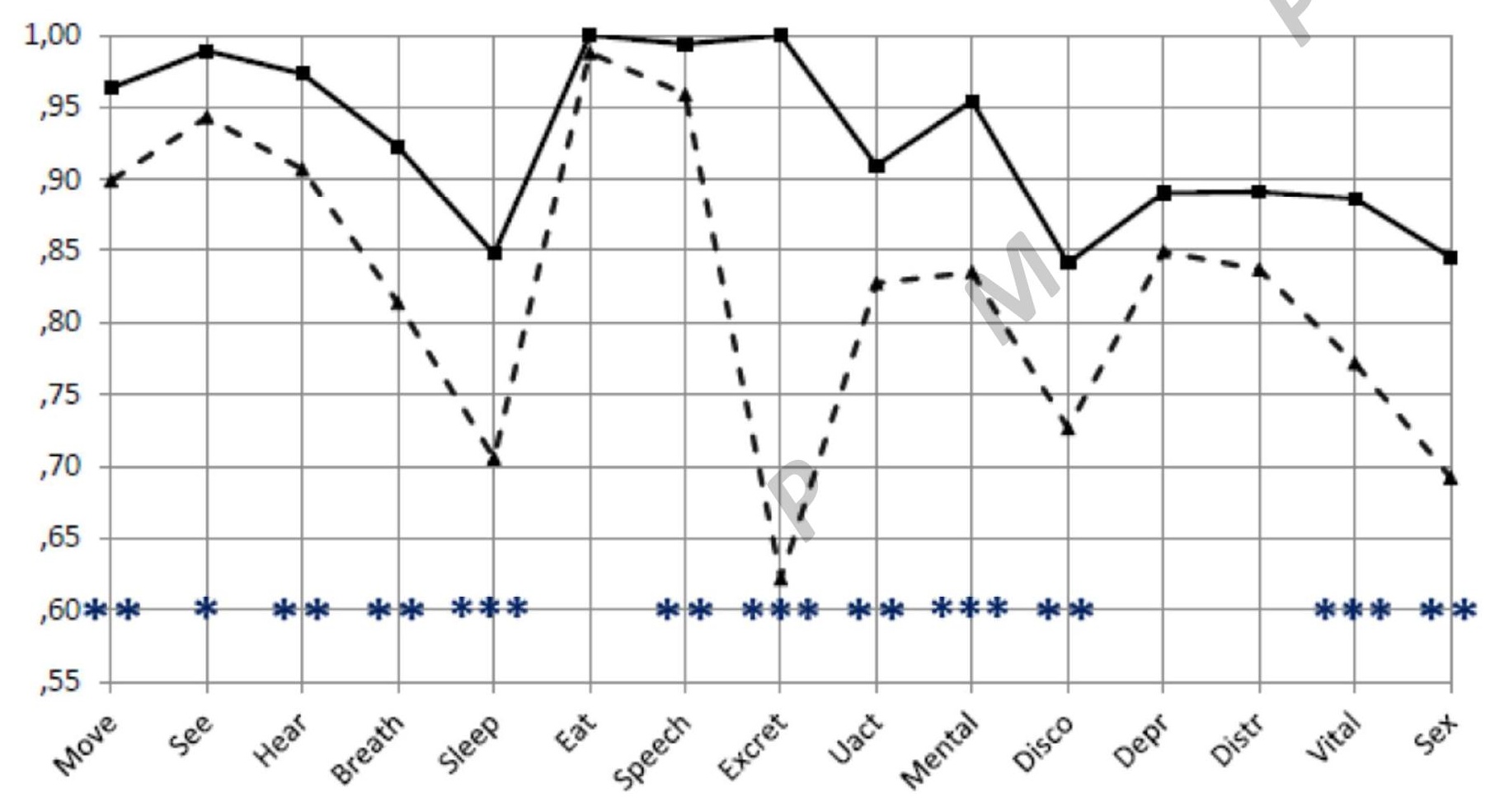

Mean 15D score

Normal excretion 0.933

Impaired excretion 0.828

$p<0.001$

- Normal excretion

- - Impaired excretion 


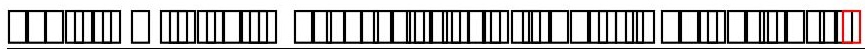

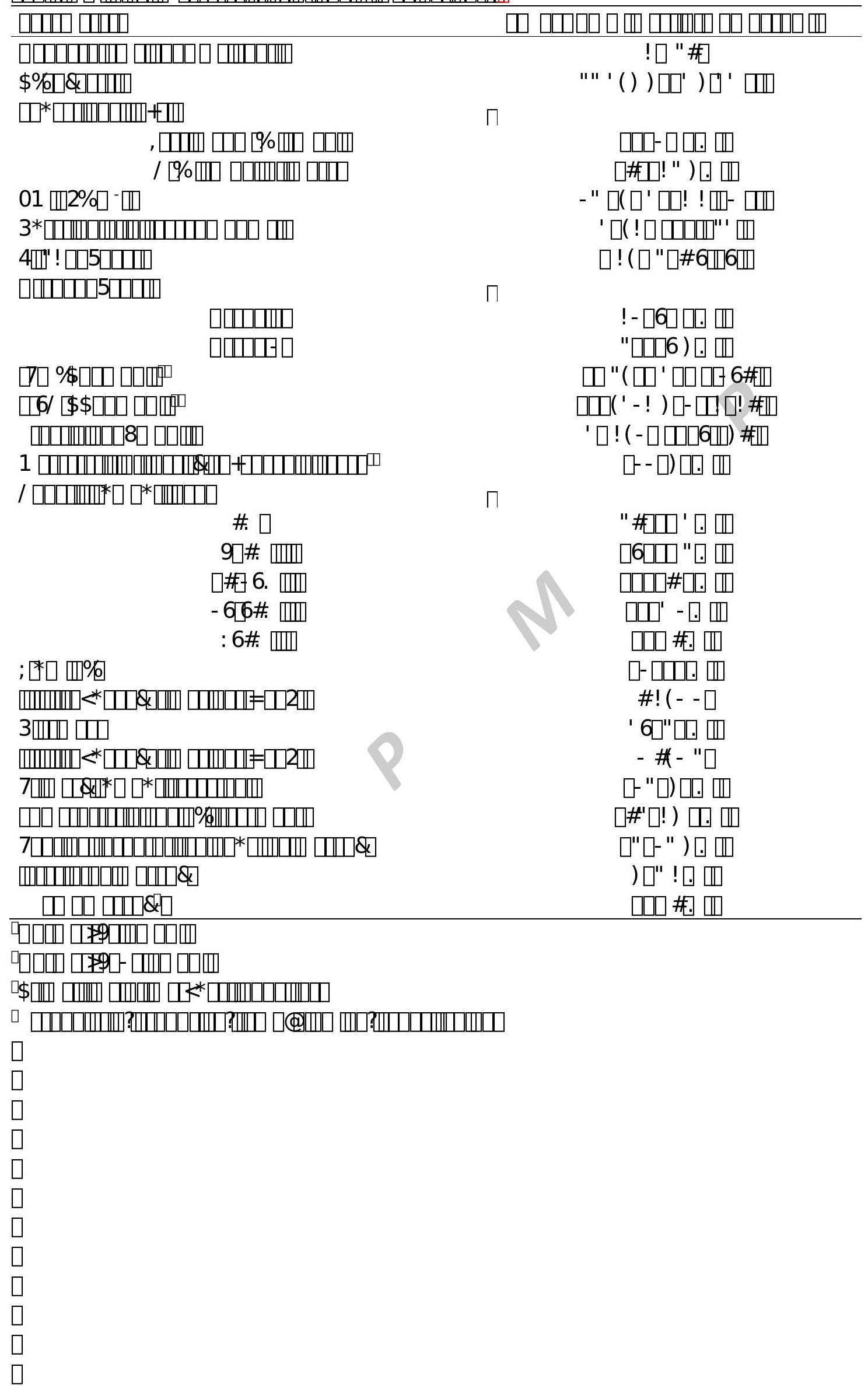


$\square$

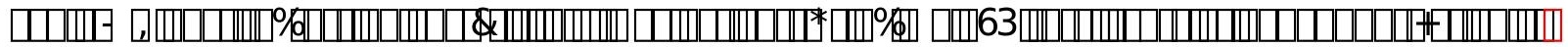
$\square$

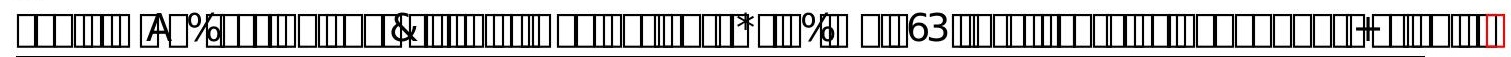

\begin{tabular}{|c|c|c|}
\hline 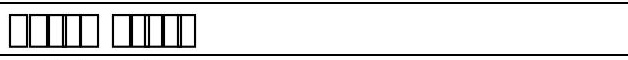 & 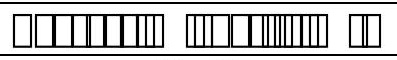 & प[t] \\
\hline 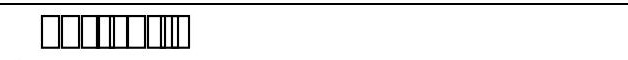 & $\#^{\prime}-6 \square$ & \#\#\#机 \\
\hline \$\% & \#\#\#口 & \#־-! ! \\
\hline पण口णा & \#\#! $\square$ & \#־-८ए \\
\hline 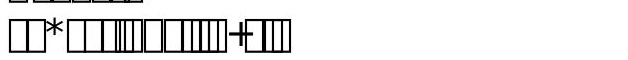 & \#\#! & \#\# [ए] \\
\hline 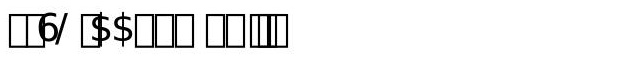 & \#\#\#邦 & \#6\#[ \\
\hline 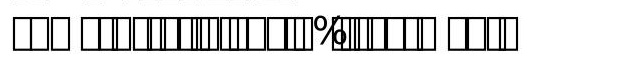 & {$[\# \#$ \# } & $\# !-! \square$ \\
\hline 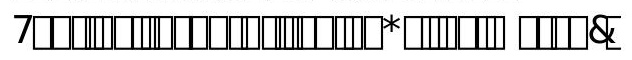 & \#㚘 & \#66' $\square$ \\
\hline 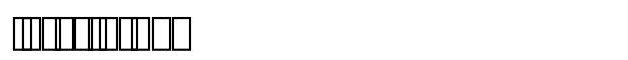 & \#\#口那 & $\# \square[\square$ \\
\hline 4丁! & \#\#\#口 & $\# !-\square$ \\
\hline , & [\#\#ロ & \#" \# \\
\hline 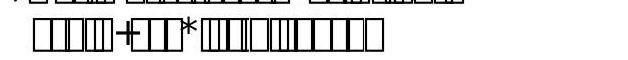 & \#\#㚘 & \#\#6! $\square$ \\
\hline 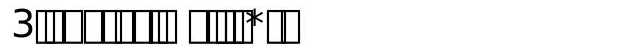 & \#\#) & \#ロ丁"口 \\
\hline 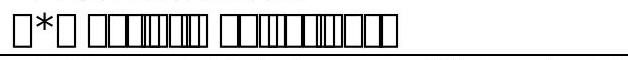 & [\#㚘) $\square$ & पएण \\
\hline
\end{tabular}

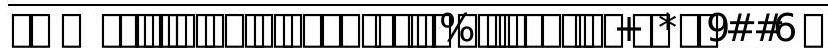

$\square$

$\square$

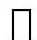

$\square$

$\square$

$\square$

$\square$

$\square$

$\square$

$\square$

$\square$

$\square$

$\square$

$\square$

$\square$

$\square$ 


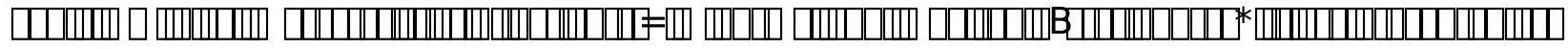

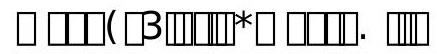

\begin{tabular}{|c|c|c|c|}
\hline 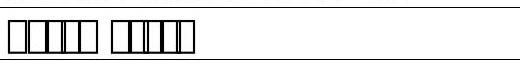 & 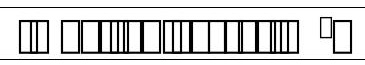 & 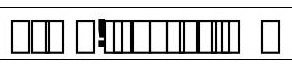 & 0 \\
\hline 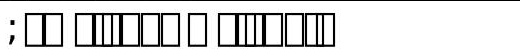 & पं प) प & -" -口 & \#ロबा \\
\hline 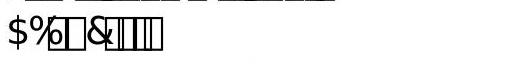 & "6)( (ए\#-口 & $" ' \square()-\#$ & \#)! ! \\
\hline 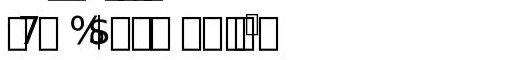 & 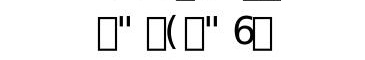 & $\square \square(-16 \square$ & \#ロप्र \\
\hline 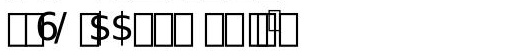 & 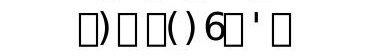 & $-6-6\left(6^{-1} ! \square\right.$ & \#回! \\
\hline 4ा"! ! Q & ०-(口ण & ०6(口'० & ૧ए"\# \\
\hline 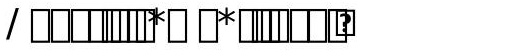 & $\sqcap$ & $\sqcap$ & $\Pi$ \\
\hline 征 & प) $\square$ ' · 四 & 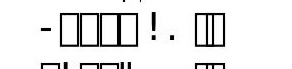 & $\Pi$ \\
\hline 9匚\#: 血 & $-^{\prime}\left[\begin{array}{ll}- & \mathrm{m}\end{array}\right.$ & ○!口" - . 四 & $\Pi$ \\
\hline 口\# 6. 血 & 'ㄱ)-. 四 & "마 ' . 四 & $\Pi$ \\
\hline - 6[6\#. 血 & ) & -마. 四 & $\Pi$ \\
\hline :6\# 血 & 마마. 四 & 口- ?. 四 & $\Pi$ \\
\hline 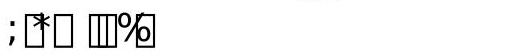 & 마미 ' & 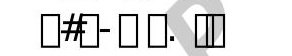 & \#\#6ए \\
\hline 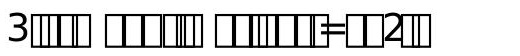 & 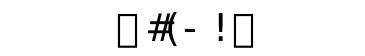 & 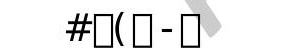 & 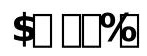 \\
\hline 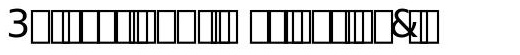 & - !(口"૨ & ○!(口耙 & $\$ \square \square[\%$ \\
\hline 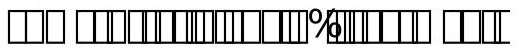 & !回"．四 & ㄷ!ㄷ. 四 & \#ए"口 \\
\hline 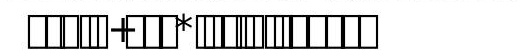 & 口" प66 - . 四 & -) प"口! . 四 & \#ロ")० \\
\hline 3ாயण口 & 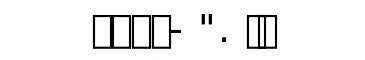 & 口\#-○○. 四 & \#---Q \\
\hline 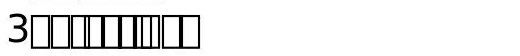 & 'ㄱ) - . 四 & 口'6. 回 & \#' '井 \\
\hline 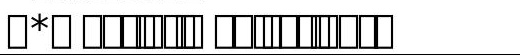 & 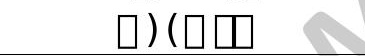 & प6(- ए & 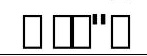 \\
\hline
\end{tabular}

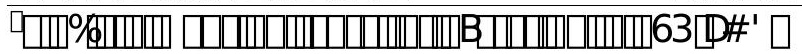

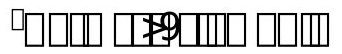

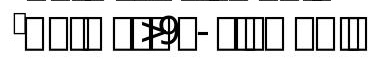

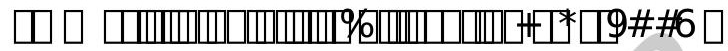

$\square$ 


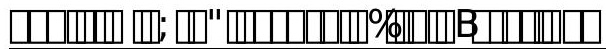

\begin{tabular}{|c|c|c|c|}
\hline 四 & 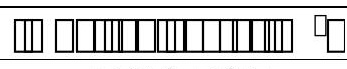 & 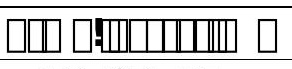 & 만 \\
\hline 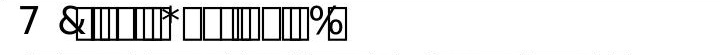 & 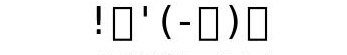 & '○井口! "૨ & प्\% \\
\hline A A & $66 "(\square ' 0$ & !) )(口"口 & पास \\
\hline A & 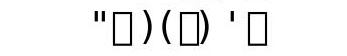 & 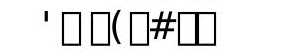 & पएष \\
\hline 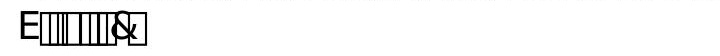 & 6'-(-\#口 & $!-\square(-\#) \square$ & पास \\
\hline 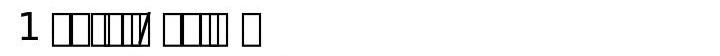 & 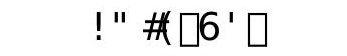 & '०'(口!) & \#\#6"ᄆ \\
\hline 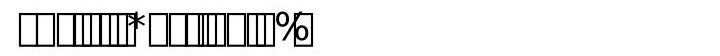 & $6(-66 \square$ & 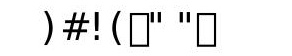 & पसाप \\
\hline 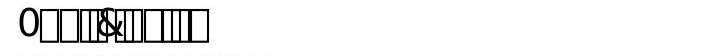 & "! प(-" ए & ' - प(口) ए & एए\% \\
\hline 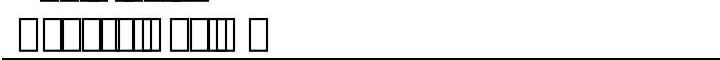 & 口) )(口)! ! & "口册口) ए & पसाप्रा \\
\hline
\end{tabular}

"प्m

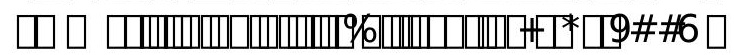




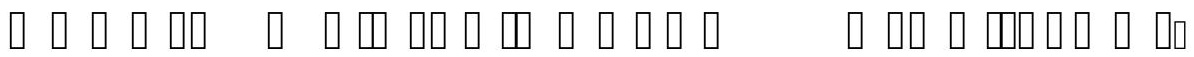

0

$\square$

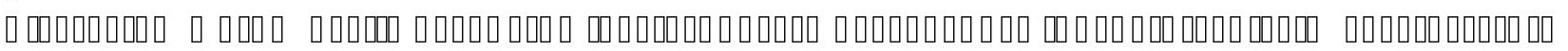

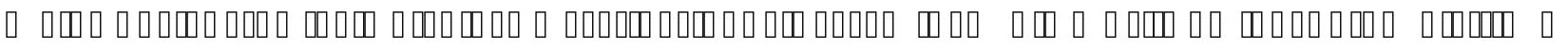

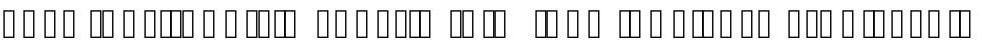

(]

ㄱ.

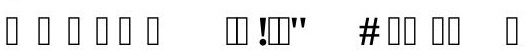

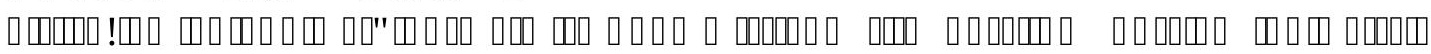

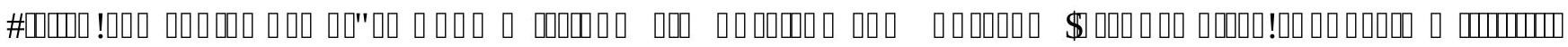

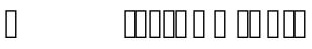

\%

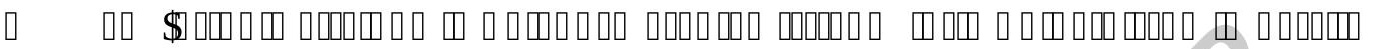

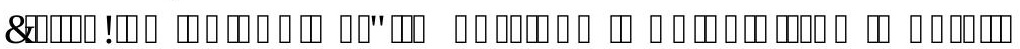

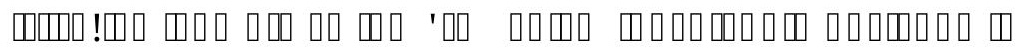
(]

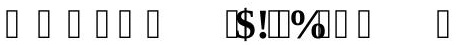

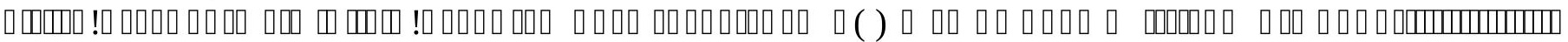

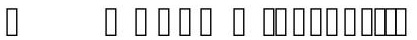

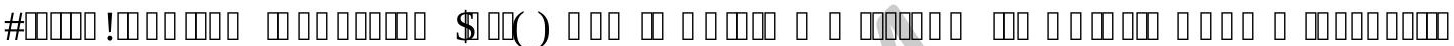

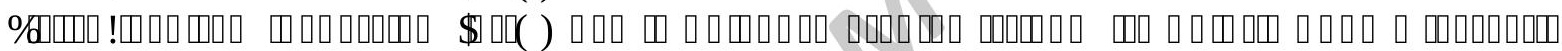

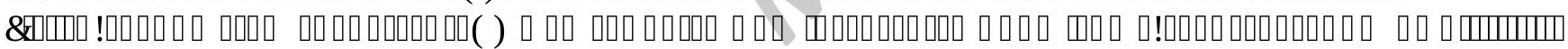

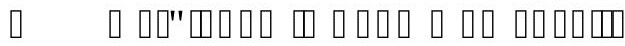

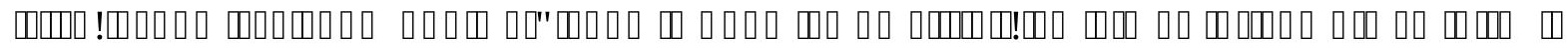
]

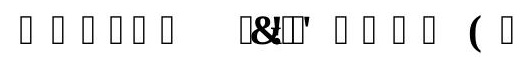

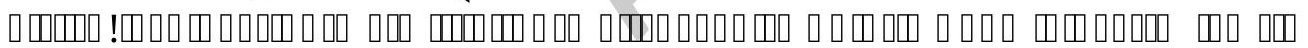

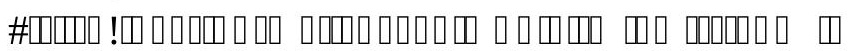

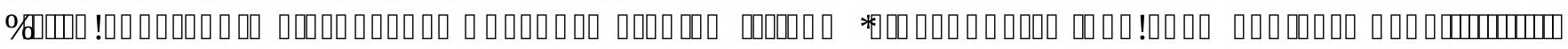

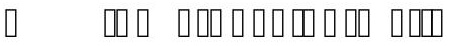

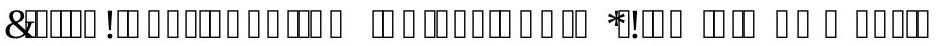

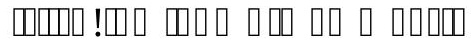

(]

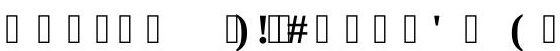

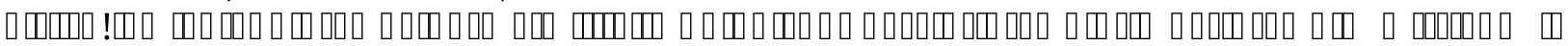

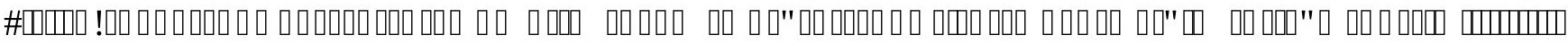

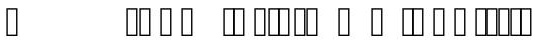

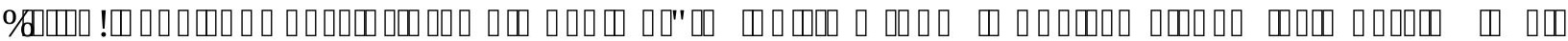

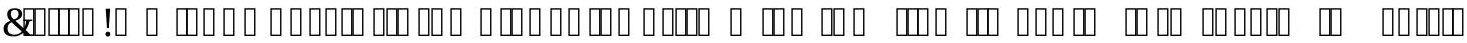

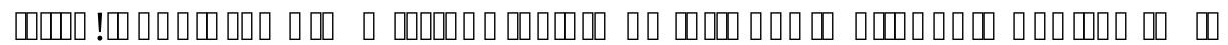

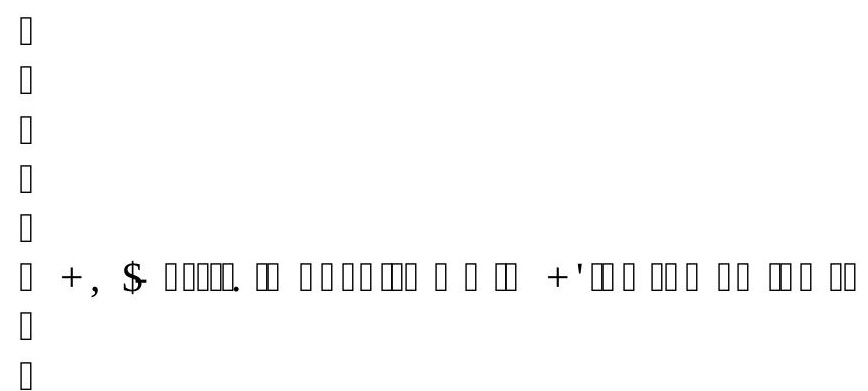




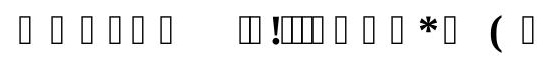

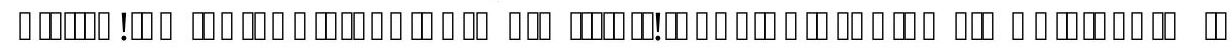

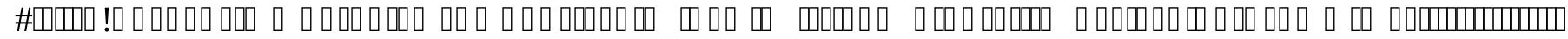

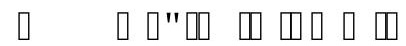

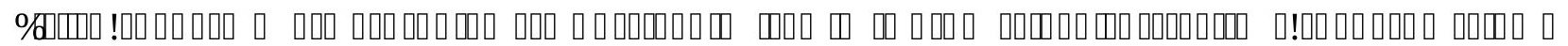

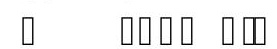

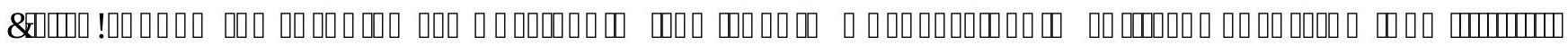

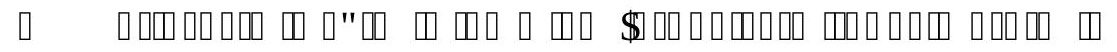

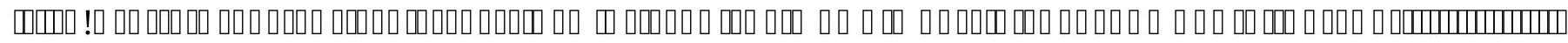

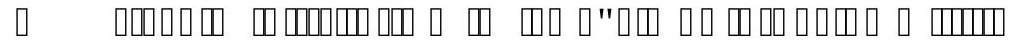

[

[

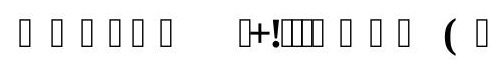

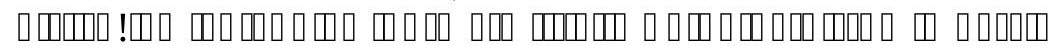

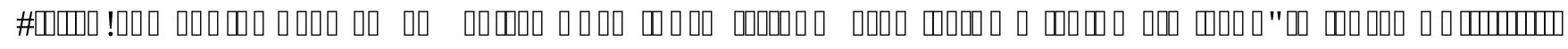

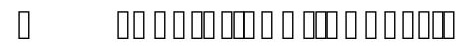

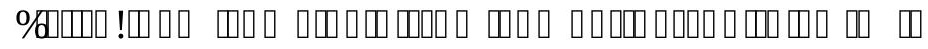

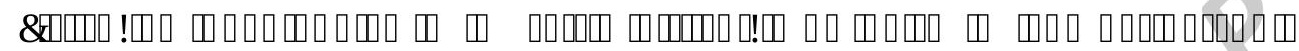

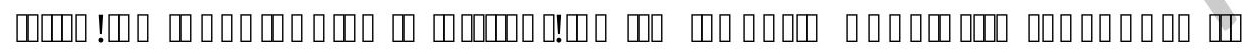

प

]

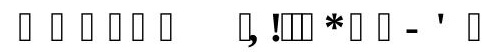

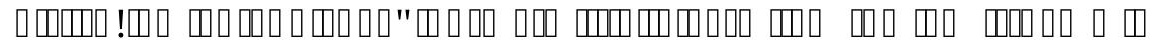

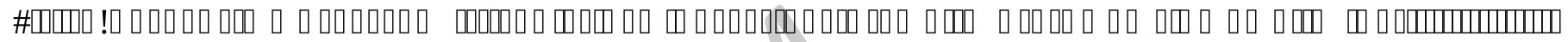

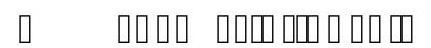

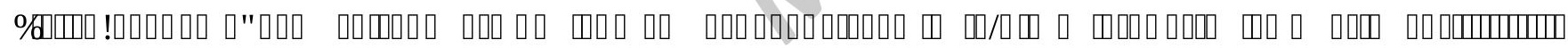

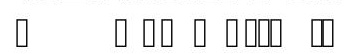

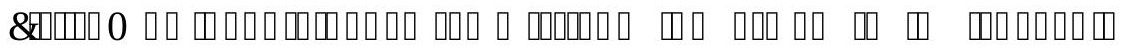

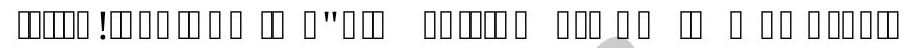

]

[

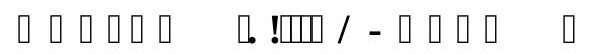

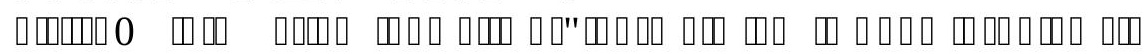

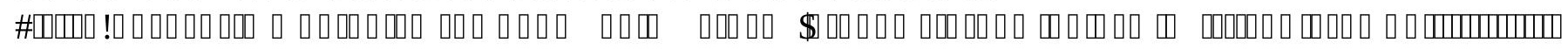

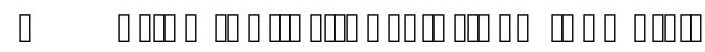

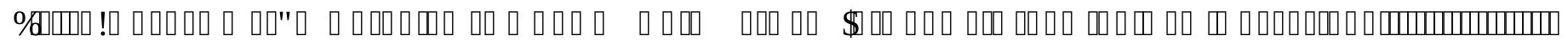

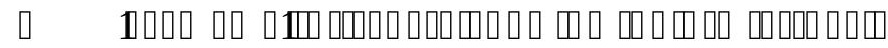

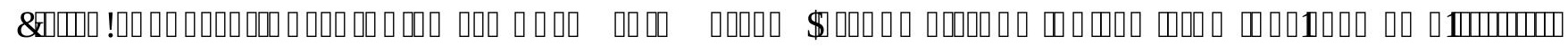

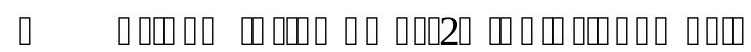

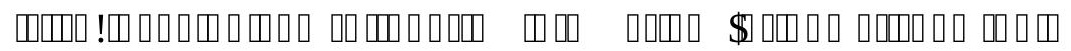

प

]

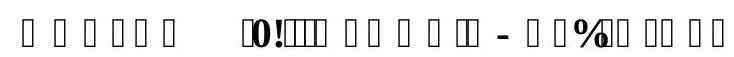

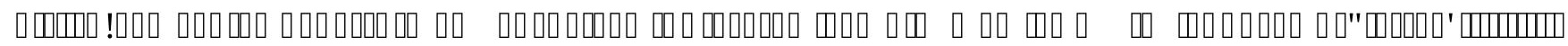

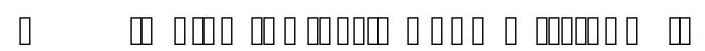

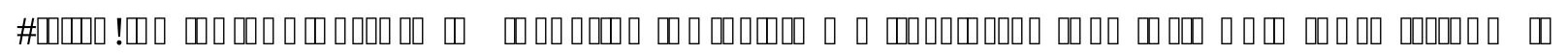

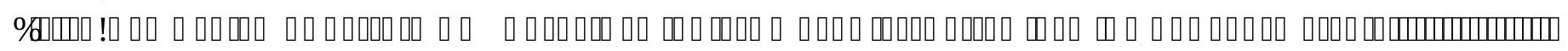

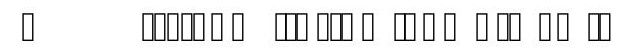

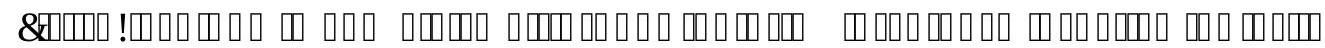

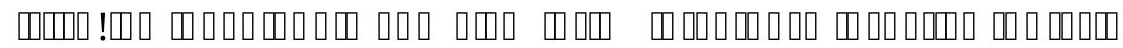

[ 


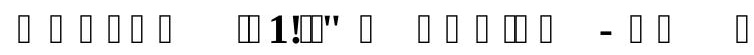

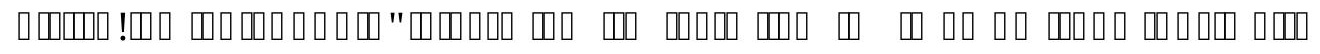

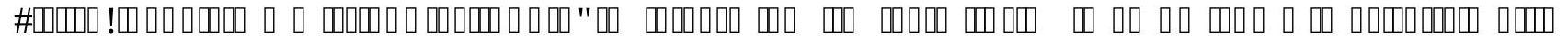

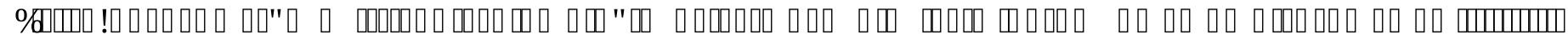

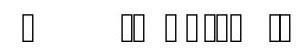

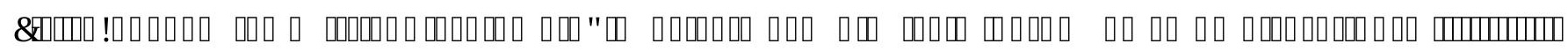

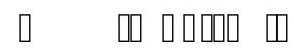

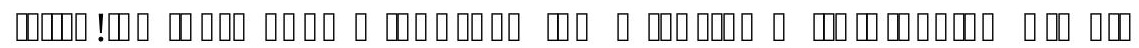
]

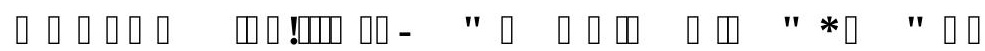

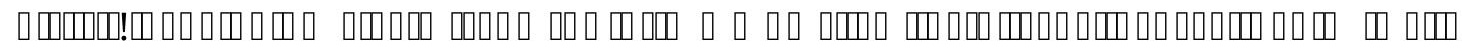

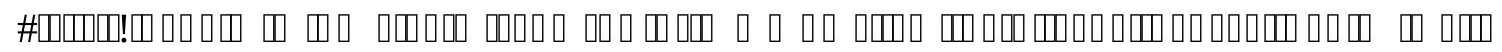

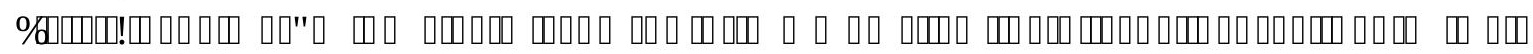

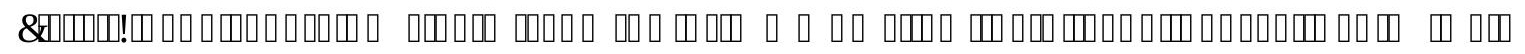

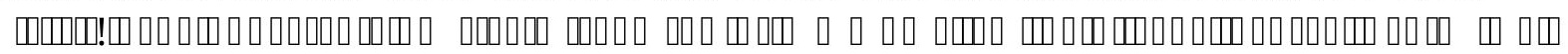
]

[

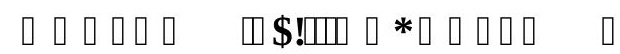

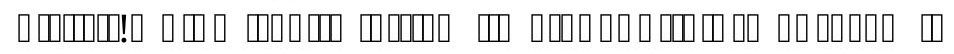

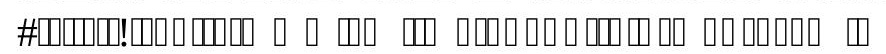

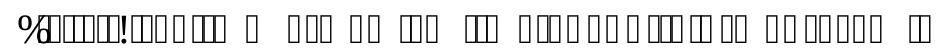

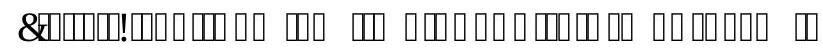

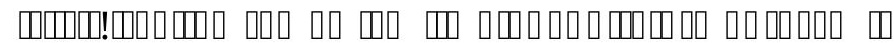

]

[

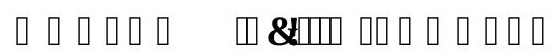

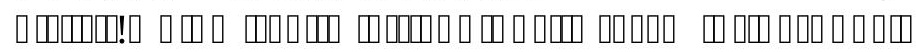

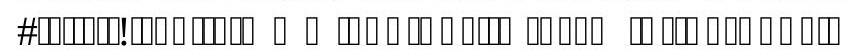

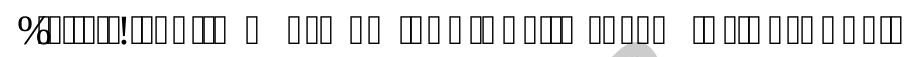

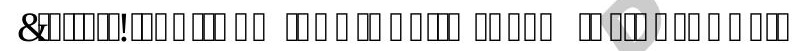

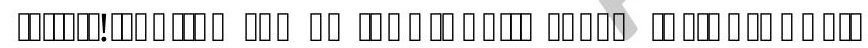

]

]

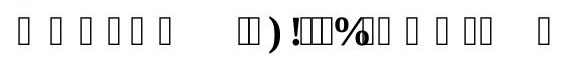

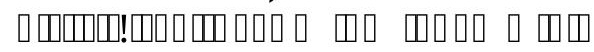

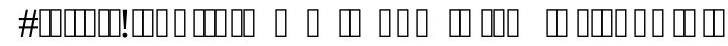

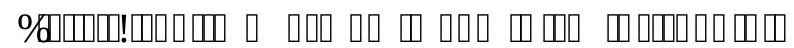

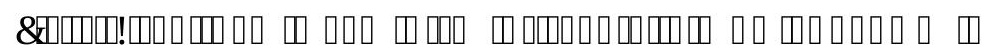

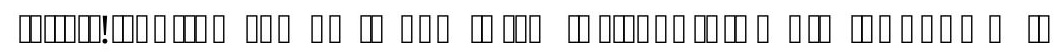

$\square$

प

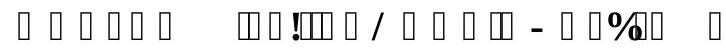

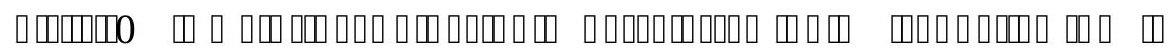

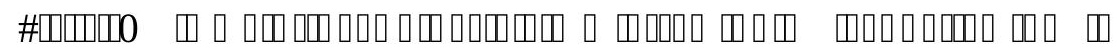

\% \%

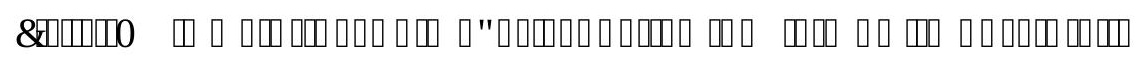

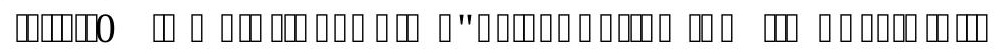




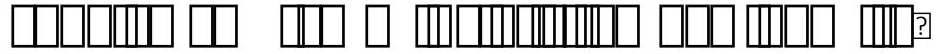 \\ $\square$

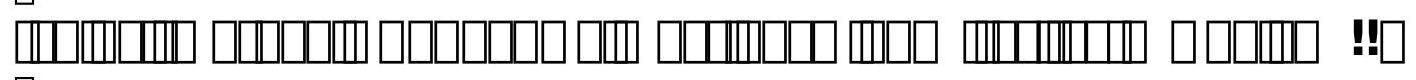
$\square$

回

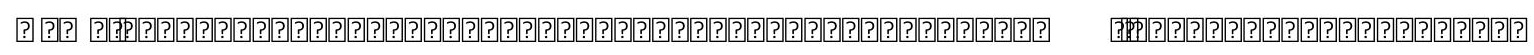
?]

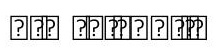

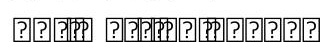

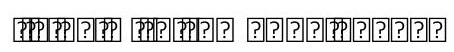

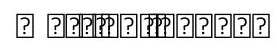

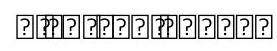

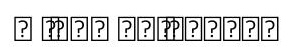

?

[ل]

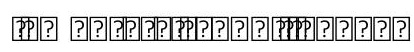

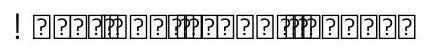

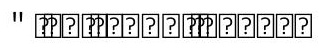

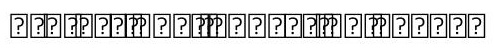

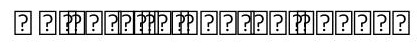

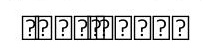

?

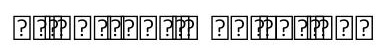

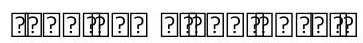

回 回 回

?

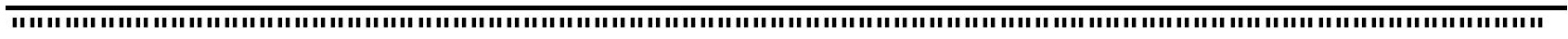

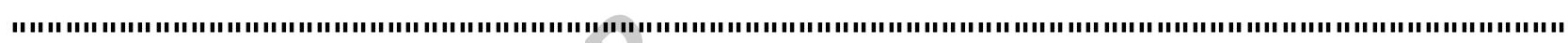

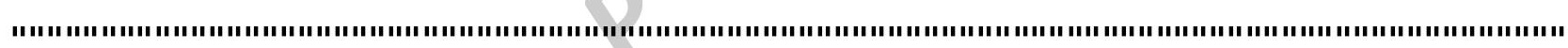

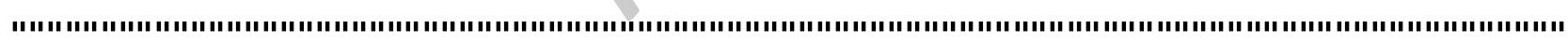

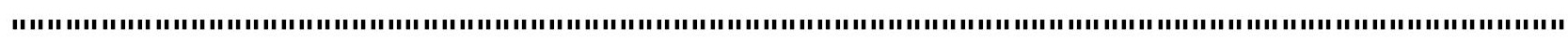
|

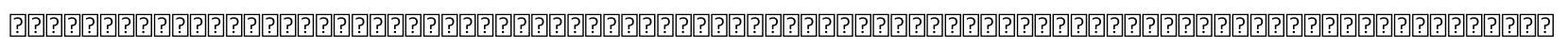
?

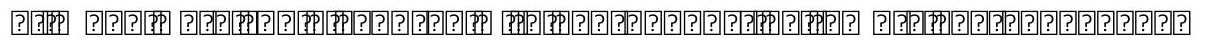

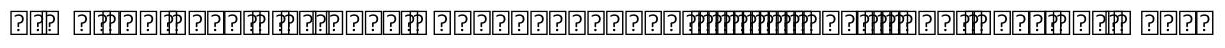

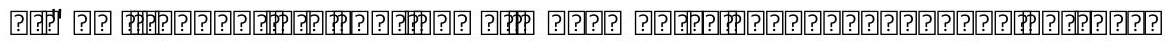

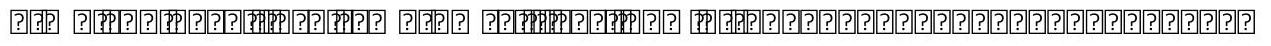

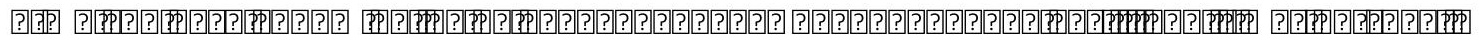

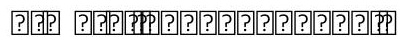

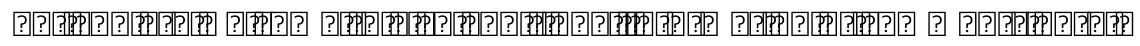
? 